\title{
Hernia umbilical através do canal de Richet
}

\author{
Communicação feita pelo academico \\ Edmundo Vasconcellos á Sociedade. \\ Arnaldo Vieira de Carvalho.
}

$\mathbf{V}^{\mathrm{s}}$

EM a presente nota chamar a attenção daquelles que se dedicam

á cirurgia para uma variedade de hernia, geralmente descuidada. e mesmo negada por certos autores. Trata-se da possibilidade de formação de hernias atravéz do canal umbilical de Richet.

$\mathrm{Na}$ extensa bibliographia compulsada nada encontramos refrerente á questão e nos tratados classicos apenas vagas e imprecisas. indicações existem.

Pelo exposto e pela importancia que lhe dá o prof. Sergio Meira, fomos levado a vir aqui registrar um caso por nós observado, na clinica do nosso mestre prof. B. Montenegro. Faremos ligeiras referencias á formação anatomica que nos occupa, bem como ao diagnostico e tratamento da hernia umbilical.

Hernia umbilical é o tumor formado pela sahida de orgão ou orgãos contidos na cavidade abdominal, atravéz do orificio umbilical, quer esse orificio seja normalmente aberto, como no embryão, quer elle esteja já obliterado ou pathologicamente destruido após o nascimento.

Dahi a divisão em hernias I congenitas e II adquiridas. Sendo que chamamos de congenitas apenas aquellas que têm para favorecelas uma predisposição de origem congenita, chamando de embryogenicas e fetaes aquellas que se dão no periodo intra - uterino. A I classe não nos interessa no momento.

Vejamos as adquiridas. Podemos dividi-las em a) da primeira. infancia e b) do adulto.

Estudaremos apenas as do adulto. Estas podem 1) ser directas, quando se fazem atravez de um orificio, que apresenta pois apenas uma dimensão, o diametro, 2) indirectas, quando se processam atravez um canal, isto é, um trajecto apresentando tres dimensões. Nesse simples detalhes de geometria rudimentar está a base da classificação. Devemos dizer que a hernia directa é sempre um hernia de fraqueza; a hernia indirecta é sempre uma hernia de força. 
Alguns auctores como Pieron e Michel negam systematicamente as indirectas; emquanto que Vidal, Bricht, Sachs, Kocher, Dechne, descrevem um verdadeiro trajecto. Jaboulay (1) dá-nos uma observação de hernia indirecta, com descripção do canal, em um jovem de 16 annos.

Anatomia - Vamos estudar summariamente o annel e a fascia.

$\mathrm{O}$ annel é o antigo orificio vascular retrahido e preenchido pelas inserções dos cordões vasculares.

Dada a presença de fibras arciformes proprias a primitiva forma quadrilatera é modificada e assim podemo-lo encontrar punctiforme, triangular como o descreveram Robin e Bonamy, ou transversal medindo 2 a $3 \mathrm{~mm}$. Quando circular mede 6 a $8 \mathrm{~mm}$. Dada a presença das fibras proprias e pela inserção dos cordões inferiores pode-se apresentar com a forma de guelo de fogo descripta por Blandin. O orificio tem uma bola de gordura e é por ahi que se faz a hernia directa. Na peripheria do annel inserem-se, em cima, a veia umbilical; em baixo, o uraco e as duas arterias umbilicaes, que se reunem formando um cordão unico chamado cordão commum.

A veia umbilical, tornada ligamento redondo do figado, bifurcase em dois feixes que se vêm inserir nos bordos lateraes do annel.

Outras vezes forma-se um nodulo conjunctivo donde partem os quatro cordões, sendo que o orificio fica situado abaixo desse nodulo. Veremos a importancia dessa forma na occasião do diagnostico.

Fascia umbilicalis - Descripta por Richet em 1856 (2) e depois muito bem estudada e descripta por Sachs (3) em 1887

"E' uma faixa fibrosa que se extende de um lado a outro da linha branca e contra a qual ella applica a veia umbilical" (Nicollas).

Richet descrevendo-a assim se exprime: "O peritonio que envolve a veia umbilical é, desde o annel até 3 a $4 . \mathrm{cm}$. acima dessa abertura, forrado por uma lamina esbranquiçada, de fibras dirigidas transversalmente e cortando em angulo recto a direcção da veia. As fibras podem ser seguidas até os bordos dos musculos rectos, onde ellas se confundem com o folheto posterior da bainha. Destinada a proteger a entrada da veia umbilical no annel, ella reforça pela sua presença a parte superior desse orificio que é desprovida de adherencias solidas"

Entre a face anterior da fascia e a posterior da bainha dos rectos forma-se o canal umbilical.

Quanto á sua significação a fascia é um espessamento da fascia transversalis, e encontra-se na maior parte dos individuos.

Hugo Sachs depois de numerosas pesquizas diz que podemos reconhecer 3 disposições de fascias:

(1) - Hernias Col. Delbet et Dentú.

(2) - Archivos, 1856 Dezembro. Veja : Richet - Anat. Med. Chir. 1860.

(3) - Die Fascia umbilicalis - Arch. Path. Anat. 1887. 
FIG.. II

$\Lambda$ - Canal de Richet

B - Fascia de Richet

C - Trajecto do sacco herniario

D-Ligamento falciforme e arteria umbilical obliterada

E - Fundo do sacco herniario direito

F - Arteria umbilical obliterada e muito atrophiada

G - Inserção da fascia

$\mathrm{H}$ - Tecido cellular pre-peritoneal

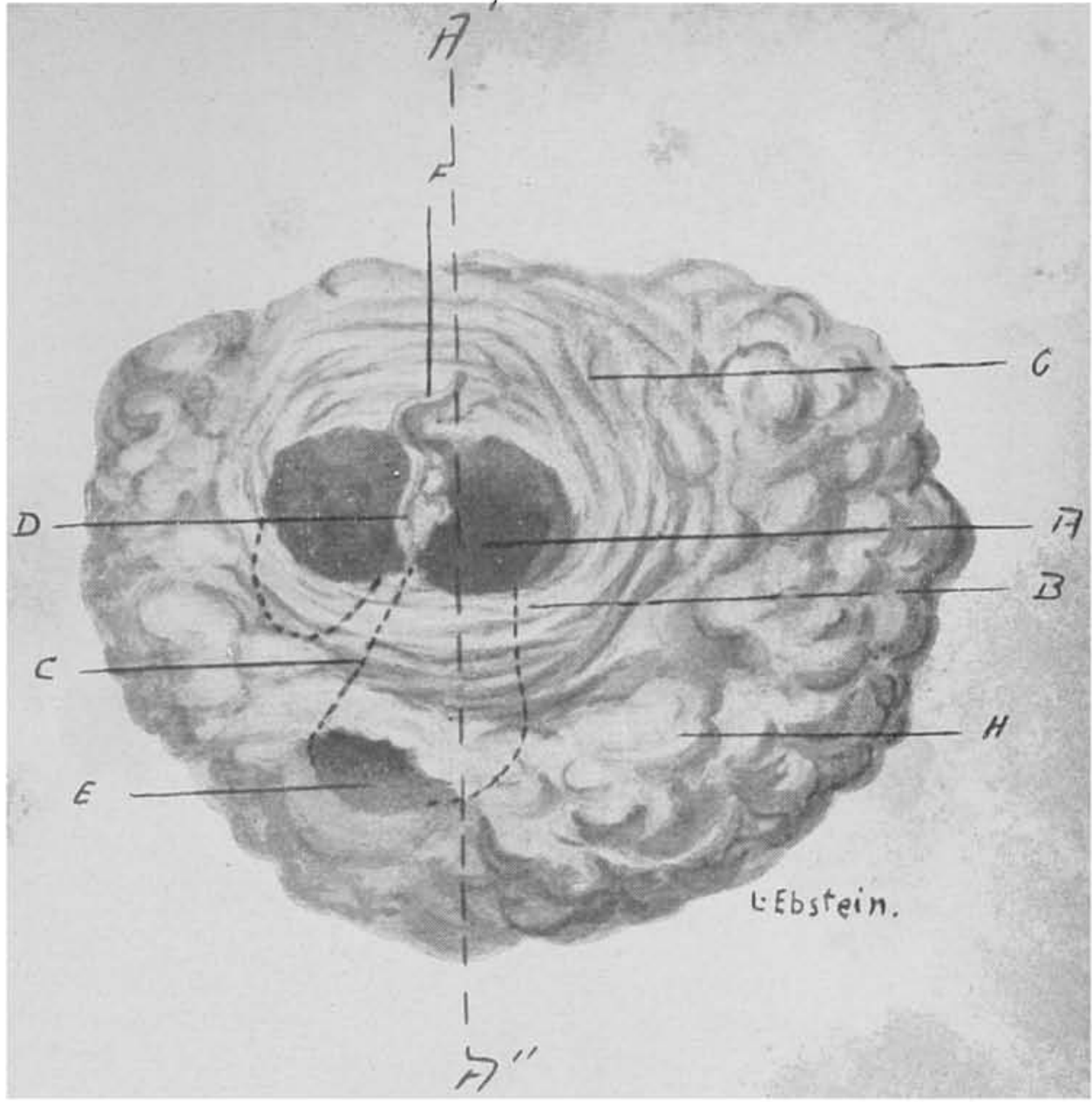

FIG. III

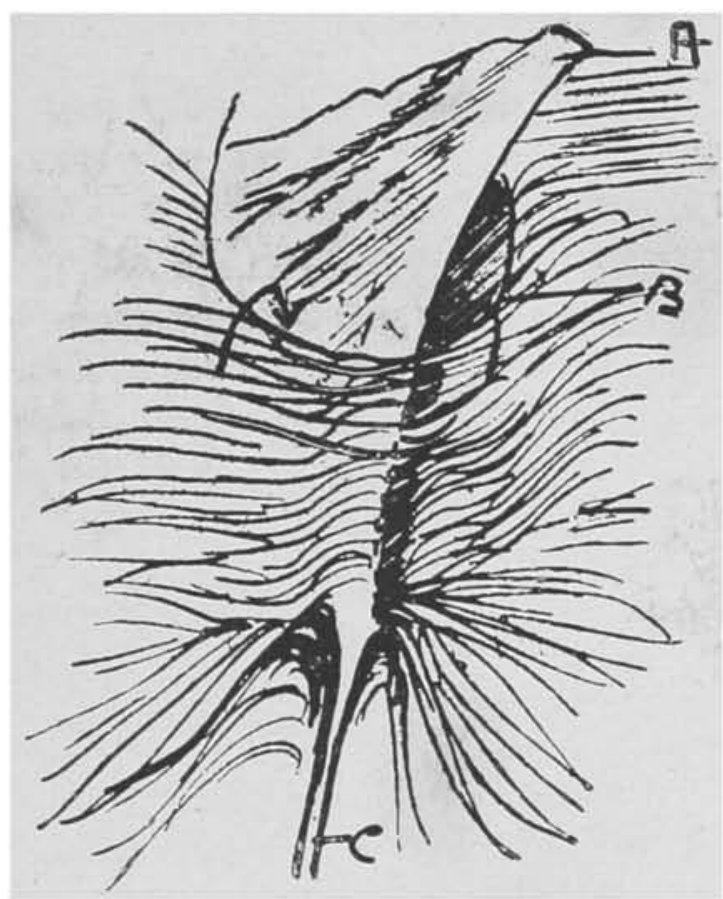

FIG. I - Fascia ombilicalis de Richet

$A$ - Ligamento redondo do figado

B - Fascia ombilicalis

C - Cordão commum

As flechas indicam a penetração da hernia.

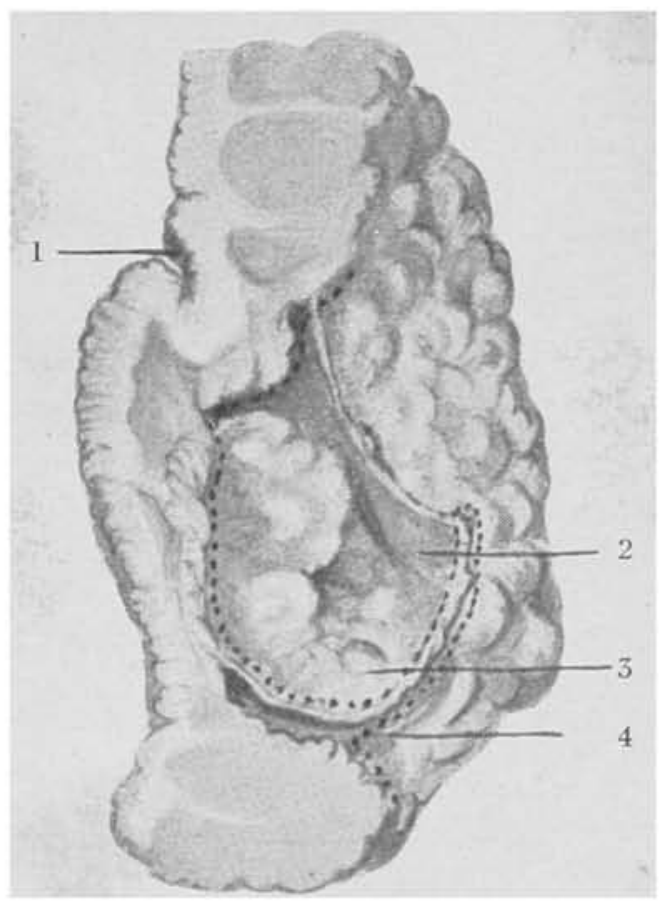

Corte feito segundo $A^{\prime} A^{\prime \prime}$ da FIG. II

1 -Umbigo

2-Sacco herniario

;-Epiploon

4-Peritoneo, em pontilhado 

I A fascia está situada muito acima ou muito abaixo do orificio; não protegee e não concorre para a formação das hernias indirectas.

II A fascia cobre todo annel e adhere nos quatro lados; protege impedindo a formação de hernias indirectas.

III $\mathrm{O}$ bordo superior ou inferior aflora o orificio umbilical e esse é o bordo livre; é a variedade propicia á formação de hernias indirectas pois só aqui ha formação de trajecto.

Sachs em 115 crianças encontrou esta ultima disposição 19 vezes. Hevadoux encontrou a fascia em $84 \%$ dos casos e em $14 \%$. este ultimo typo.

Veja-se fig. 1.

obSERVAÇÃo - A. P. Casada - Espanhola - 39 annos.

Dos seus antecedentes familiares e pessoaes nada ha que nos possa interessar.

Molestia actual - Teve inicio ha 7 annos por occasião dum esforço violento. Nessa occasião tinha dois filhos sendo que o ultimo com 6 mezes.

Estava muito fraca e abatida. Conta que na occasião em que procurava levantar uma bacia cheia de roupa molhada, sentiu dor violenta na região umbilical, sentiu-se enfraquecer. A dor irradiava-se para o epigastro dando a sensação de forte agulhada.

Nas occasiões em que come de mais sente dor mais forte, ja tendo acontecido vomitar a refeição, sendo que isso melhora.

Teve nauseas, vomitos e muita dor de cabeça. Acamou por dois dias. Na mesma occasião notou que se tinha formado uma saliencia ao nivel do umbigo, comparavel a uma avelã.

Desde então as dores nunca cessaram, augmentavam com o esforço, sendo que havia vezes que precisava ficar deitada o dia todo.

O volume do tumor umbilical foi crescendo aos poucos, e como as dores persistissem resolveu procurar o Prof. B. Montenegro.

Exame physico - Trata-se de uma senhora de constituição robusta, paniculo adiposo bastante desenvolvido, revelando á inspecção do abdomen um tumor do tamanho de um ovo de pato, ao nivel do umbigo. Tumor solido, liso, maciço á percussão e não reductivel.

Interrogatorio sobre os diff. apparelhos: Tem frequentes dores de cabeça - Tem bom apetite e come bem. Ja vomitou como ficou dito. Intestinos funccionavam bem.

- Internada no Sanatorio de Santa Catharina, foi submettida á intervenção cirurgica procedida pelo Prof. B. Montenegro e por nós auxiliada, no dia 7-2-927. Obtendo alta curada em 17-2-927.

OPERAÇÃo: consistiu em incisão curvilinea e abraçando a porção superior da região umbilical, e numa extensão de 15 cent. no maior eixo, horizontal. Incisão inferior symetrica. Ambas attingindo pelle e tecido cellular sub-cutaneo. Descollamento do retalho. Isolamento do annel umbilical a bisturi e tesoura curva. Verificado ser uma her- 
nia epigloica adherente ao fundo do sacco foi feita reseç̧ão dessa porção do epiploon. Exploração da parede em redor. Fechamento do peritonio a cat-gut n. ${ }^{2}$ 2. Reconstituição da parede por planos com approximação dos musculos rectos.

Capitonage da gordura. Na pelle foram collocados "aggrafes" e crina. - Cicatrização "per primam"

Anatomia pathologica: - Examinada a peça vimos tratar-se duma hernia indirecta pois bastante espessa e bem visivel apparecia a fascia de Richet. $\mathrm{O}$ canal umbilical dilatado apresentava ainda por"ções adherentes de epiploon. A hernia apresentava um duplo sacco como mostra a figura II, sendo separados pelo ligamento redondo e o peritonio que formava meso.

Fizemos um corte segundo AA', reproduzido na figura III mostrando perfeitamente a fascia, o canal e porções de epiploon.

CONSIDERAÇõES - Quanto ao diagnostico de hernia indirecta, podia ser feito? Assim parece á primeira vista. O umbigo apresentava-se na parte superior do tumor e fortemente retrahido. Abaixo delle uma saliencia globosa. Poderiamos raciocinar que existindo de um lado a parede do outro a fascia o conteúdo herniario repellia a parede do ventre e o umbigo era retrahido pela uraca e as duas arterias; pois sabemos que nas hernias directas a cicatriz do umbigo desapparece progressivamente distendido, sendo que o vertice do tumor é o centro do umbigo. Vamos ver que no entanto pode-nos induzir a erro o facto ja assignalado dos quatro cordões partirem dum nucleo situado acima do orificio. Aqui compreende-se que o conteudo faz saliencia mas a cicatriz é repuxada pelos cordões inserindo-se no nodulo.

Um cuidado que é preciso ter uma vez o sacco resecado é a exploração minuciosa da parede, pois no caso de inserção baixa da fascia o sacco pode ser duplo, sendo que um constitue a hernia directa, emquanto que o outro se insinua no canal umbilical. $\mathrm{O}$ operador inadvertido puchando o primeiro sacco deixa no interior do abdomem uma hernia properitonial capaz de se estrangular e de difficil diagnostico.

Refere o Prof. Sergio Meira um caso desta natureza, no qual após a resecção do sacco da hernia umbilical o dedo introduzido na cavidade abdominal foi esbarrar num plano resistente fechado em baixo e contendo o epiploon no interior.

Nesses casos impõe-se o augmento da incisão e resecção do novo sacco.

- Quanto á technica cremos que dentre as innumeras ideadas pela imaginação dos cirurgives, a que mais raccional se apresenta e a que melhores resultados forneece, é aquella que procura sem artificios illusorios, reconstituir anatomicamente a parede em planos separados com aproximação dos musculos rectos. Sendo que a hernia aqui depende de formações anatomicas locaes, e não de fraqueza geral da parede, uma vez essas formações retiradas, nada contra-indica o restabelecimento anatomico por planos. 